\begin{tabular}{|c|l|}
\hline Title & Biochemical Composition and Lipid Compositional Properties of the Brown A Iga Sargassum horneri \\
\hline Author(s) & Hossain, Zakir; Kurihara, Hidey uki; Takahashi, Koretaro \\
\hline Citation & $\begin{array}{l}\text { Pakistan Journal of Biological Sciences, 6(17), 1497-1500 } \\
\text { https://doi.org/40.3923/jjbs.2003.1497.1500 }\end{array}$ \\
\hline Issue Date & 2003 \\
\hline Doc URL & http://hdl.handle.net/2115/42570 \\
\hline Type & article \\
\hline File Information & takahashi_PJBS6_1497.pdf \\
\hline
\end{tabular}

Instructions for use 
Pakistan Journal of Biological Sciences 6(17): 1497-1500, 2003

ISSN 1028-8880

(C) 2003 Asian Network for Scientific Information

\title{
Biochemical Composition and Lipid Compositional Properties of the Brown Alga Sargassum horneri
}

\author{
Zakir Hossain, Hideyuki Kurihara and Koretaro Takahashi \\ Laboratory of Biomolecular Chemistry, Graduate School of Fisheries Sciences \\ Hokkaido University, Hakodate 041-8611, Japan
}

\begin{abstract}
Biochemical composition of brown alga Sargassum horneri was investigated by determination of moisture, protein, carbohydrate, ash, simple lipids and glycolipids. Fatty acid composition of simple lipids and glycolipids was determined by gas chromatography. The algal specimens were collected in two different months, January (sample-1) and February (sample-2). Moisture contents were 86.94 and $87.00 \%$ in sample-1 and sample-2, respectively. Protein, carbohydrate and ash contents were $22.94,19.93$ and $32.00 \%$ of the dry sample1 , respectively, while the contents of the dry sample- 2 were $21.96,20.81$ and $33.58 \%$, respectively. Glycolipids were 1.38 and $1.96 \%$ of the dry sample- 1 and sample- 2 , respectively, whereas 2.45 and $2.75 \%$ when the samples were digested with the abalone Haliotis discus enzyme. Of the glycolipids obtained, MGDG, DGDG and SQDG were nearly 15,15 and $68 \%$, respectively. The major fatty acids in simple lipids were 16:0, 18:1 and 22:0. The major fatty acids in individual lipid class were 16:0, 18:1, 20:1, 20:4 and 20:5 in MGDG, 16:0, 20:0, 20:4 and 20:5 in DGDG and 16:0, 18:0, 18:1, 18:2 and 20:4 in SQDG. S. horneri is a potential source of valuable glycolipids .
\end{abstract}

Key words: Sargassum horneri, glycolipids, MGDG (monogalaclosyl diachlglycerol), DGDG (digalaclosyl diacyldlycerol), SGDG (sulfoquinovosyl diacylglycerol)

\section{Introduction}

Japan is favoured with a rich variety and abundance of seaweed. Undaria, Hizikia, Sargassum, Eisenia and Ecklonia are found abundantly in warmer water from Honshu to Kyushu islands in Japan. Surrounded by the sea, the Japanese have always relied heavily on seaweeds. Japanese use it in their diets more than any other people.

Sargassum is a large genus with more than 150 species described, occurring in tropical, subtropical and temperate zones of both hemispheres (Nizamuddin, 1962). It is the most conspicuous brown algas in the tropical and subtropical waters, ranging from mid-littoral to sublittoral zones. Sargassum horneri is found in the coast of Pacific ocean and the adjoining seas of Formosa, China, Korea and Japan (Tokida and Masaki, 1959).

Algae represent valuable sources of a wide spectrum of complex lipids with different potential applications. The lipids containing polyunsaturated fatty acids are especially interested in various applications. Essential fatty acids are precursors of postaglandins and, as such are becoming increasing by importance in the pharmaceutical industry (Borowitzka, 1988 and Becker, 1994). Some of these compounds are usually rare in terrestrial plants and animals but are present in relatively large amounts in some species of algae and fish (Richmond, 1990; Becker, 1994 and Caughey et al., 1996).
They have beneficial effects on heart diseases, Parkinson disease, multiple sclerosis, inflammatory diseases, premenstrual syndrome, plasma cholesterol levels, cancers and others (Borowitzka, 1988; Callegari, 1989; Henrikson, 1989; Richmond, 1990 and Rodriguez and Guerrero, 1992). In this paper, the biochemical composition and fatty acid contents of the brown alga S. horneri are described.

Materials and Methods

Source of sample: The brown alga $S$. horneri was collected from Japan sea of Toyama Prefecture, Japan, twice on 10th January (sample-1) and on 6th February (sample-2) in 2002. The algal specimens were maintained at $-20^{\circ} \mathrm{C}$ until use.

Measurement of biochemical composition: Moisture was determined by drying $100 \mathrm{~g}$ samples in a freeze dryer (FD5, Tokyo Rikakikai, Co. Ltd., Japan) for $72 \mathrm{~h}$. Other determinations were carried out using the freeze-dried samples. Protein content was determined according to the method of Kjeldhal. Carbohydrate was analysed by anthrone-sulfuric acid method with glucose as a standard. Total lapid was extracted by the method of Bligh and Dyer (1959). For ash determination, $0.5 \mathrm{~g}$ samples were maintained at $600^{\circ} \mathrm{C}$ for $8 \mathrm{~h}$ in a muffle furnace (FO200, Yamato Scientific Co. Ltd. Japan). 
Separation of glycolipids and simple lipids from total lipids: The extracted total lipids was applied to silica gel column chromatography and eluted with chloroform to afford simple lipids. Lipids were monitored on thin layer chromatography (TLC) by comparing each spol with authentic lipid standards. TLC plates were developed with hexane/diethyl ether/acetic acid $(70: 30: 1, \mathrm{v} / \mathrm{v} / \mathrm{v})$ for simple lipids and chloroform/methanol/water $(65: 25: 4, \mathrm{v} / \mathrm{v} / \mathrm{v})$ for glycolipid analysis, respectively. Acetone was then applied to the same silica gel column to collect simple lipids and glycolipids. But simple lipid was absent and negligible amount of MGDG was found in acetone fraction. Finally, methanol was used to the same silica gel column to afford glycolipids.

Removal of chlorophyll from simple lipids: Silica gel SepPak vac-12cc (Water Corporation, Massachusetts, USA) was used for removal of chlorophyll. Firstly, Sep-Pak cartridges were washed with n-hexone $(20 \mathrm{ml} n-$ hexane/cartridge). Hexane solution of the simple lipidcontaining fraction was subjected on silica gel cartridge and eluted with n-hexane. During the elution, firstly only simple lipids came out. And then a mixture of simple lipids and chlorophyll were eluted off. The simple lipids and the mixture of simple lipids and chlorophyll were preserved separately. The mixture was separated seven times in the same way to divide both the simple lipids and chlorophyll completely.

Separation of monogalactosyldiacylglycerol (MGDG), digalactosyldiacylglycerol (DGDG) and sulfoquinovosyldiacylglycerol (SQDG) in glycolipid fraction: $M G D G, D G D G$ and SQDG were separated by TLC on $20 \times 20 \mathrm{~cm}^{2}$ preparative glass plates coated with silica gel 60 (Merck). Chromatography was carried out in glass jar under an air atmosphere in darkroom. Lipids were separated with a developer of chloroform $/$ methanol/water $(65: 25: 4, \mathrm{v} / \mathrm{v} / \mathrm{v})$. The bands of lipids were visualized under UV light in dark room. The lipid individual bands were scraped off and immediately eluted with methanol. Methanol elution was evaporated and dissolved in chloroform/methanol/water $(10: 5: 3, \mathrm{v} / \mathrm{v} / \mathrm{v})$ in separatory funnel for over night at $4^{\circ} \mathrm{C}$. Chloroform layer was collected, evaporated and each lipid was recovered, then the percentage of samples were calculated.

Digestion of $S$. horneri with abalone enzyme: Crude enzyme was collected from the digestive tract of fresh abalone. Shell was opened and digestive tract was cut by scissor. After cutting the digestive tract, inner fluid containing enzymes was started to come out drop by drop and consequently tract was washed with phosphate- buffered saline. Collected enzyme solution was preserved with adding $0.1 \%$ sodium azide at $4^{\circ} \mathrm{C}$. One gram of each $S$. horneri sample was taken in test tube and was dipped in abalone enzyme solution. Tubes were placed in water bath at $37^{\circ} \mathrm{C}$ with shaking rate of 50 shakes $\mathrm{min}^{-1}$ for $48 \mathrm{~h}$. After $48 \mathrm{~h}$, total lipids were extracted according to the Bligh and Dyer (1959) method with slight modification. Total lipids were then eluted over Sep-Pak cartridges with chloroform, acetone and methanol. All of chloroform, acetone and methanol fractions were monitored on TLC. Methanol fraction was mainly composed of glycolipids and percentages of glycolipids were calculated.

Fatty acid composition analysis: Fatty acid methyl esters were analysed by gas chromatography with a $3 \mathrm{~mm} \times 300$ $\mathrm{cm}$ glass column packed with Unisole 3000 (GL Sciences, Tokyo, Japan) on uniport C (80-100 mesh) and with flame ionization detection. The used instrument was Hitachi 163 gas chromatograph (Ibaraki, Japan). The temperatures of column, detector and injector were 210,250 and $240^{\circ} \mathrm{C}$, respectively. The identification of fatty acids was determined by comparing the peak retention times with authentic standards (Sigma).

\section{Results and Discussion}

The proximate compositions of Sargassum horneri are shown in Table 1. Moisture contents in sample-1 (86.94\%) and sample-2 (87.0\%) were nearly similar. Protein contents were $22.38 \%$ and $21.96 \%$ of dry sample- 1 and sample-2, respectively. Vagas et al. (1998) reported that the protein content was about $40 \%$ for filamentous $\mathrm{N}_{2}$-fixing cyanobacteria. In the present experiment, carbohydrate contents in both samples were about $20 \%$, nearly similar to that of protein. But carbohydrate content was about half to that of protein for most of the strains of $\mathrm{N}_{2}$-fixing cyanobacteria (Vagas et al., 1998). Ash contents accounted $32 \%$ and $33.58 \%$ in sample- 1 and sample-2, respectively, whereas Vagas et al. (1998) accounted 5.5\% to $11.2 \%$ ash for most of the strains of $\mathrm{N}_{2}$-fixing cyanobacteria. There were little differences in protein, carbohydrate and ash contents in sample-1 and sample-2. Ricketts (1966) reported that protein ranged from $24-46 \%$, lipid $14-48 \%$ and carbohydrate $5-57 \%$ of various golden brown algae in dry weight basis. Lipids and carbohydrate contents should obviously be very variable depending upon the state of nutrition of cells (Ricketts, 1966). The findings of present experiment coincide well with that of protein and carbohydrate contents reported by Ricketts (1966) who worked with golden brown algae. But lipid was 10-30 folds higher than that of Ricketts (1966). Simple lipids (with chlorophyll) were $0.82 \%$ and $0.96 \%$ of dry sample-1 and sample-2, respectively, while $0.19 \%$ and 
Pak. J. Biol. Sci., 6 (17): 1497-1500, 2003

Table 1: Proximate compositions of the brown algae S. horneri

\begin{tabular}{|c|c|c|c|}
\hline \multirow[b]{2}{*}{ Property } & \multirow{2}{*}{$\begin{array}{l}\text { Condition } \\
\text { of samples }\end{array}$} & \multicolumn{2}{|l|}{$\%$} \\
\hline & & Sample-1 & Sample-2 \\
\hline Moisture & $\mathrm{W}^{\mathrm{a}}$ & 86.94 & 87.00 \\
\hline Protein & $D^{a}$ & 22.38 & 21.96 \\
\hline Carbohydrate & $D^{a}$ & 19.93 & 20.81 \\
\hline Ash & $\mathrm{D}^{\mathrm{a}}$ & 32.00 & 33.58 \\
\hline $\begin{array}{l}\text { Simple lipid } \\
\text { (with Chlorophyll) }\end{array}$ & $\mathrm{D}^{\mathrm{a}}$ & 0.82 & 0.96 \\
\hline $\begin{array}{l}\text { Simple lipid } \\
\text { (with Chlorophyll) }\end{array}$ & $\mathrm{W}^{\mathrm{a}}$ & 0.19 & 0.20 \\
\hline $\begin{array}{l}\text { Simple lipid } \\
\text { (without Chlorophyll) }\end{array}$ & $\mathrm{W}^{\mathrm{a}}$ & 0.05 & 0.05 \\
\hline Glycolipids & $D^{a}$ & 1.38 & 1.96 \\
\hline $\begin{array}{l}\text { Glycolipids assisted } \\
\text { With abalone } \\
\text { digestive enzymes }\end{array}$ & $\mathrm{D}^{\mathrm{a}}$ & 2.45 & 2.75 \\
\hline
\end{tabular}

Table 2: Fatty acid composition of simple lipid, MGDG, DGDG and SQDG of $S$. Horneri

\begin{tabular}{lllll}
\multicolumn{5}{c}{ SQDG of $S$. Horneri } \\
\hline & $\%$ & & & \\
& - & & & \\
Fatty acid & Simple lipid & MGDG & DGDG & SQDG \\
\hline $\mathrm{C}_{10: 0}$ & 2.10 & -- & -- & -- \\
$\mathrm{C}_{11: 1}$ & 1.64 & -- & -- & -- \\
$\mathrm{C}_{13: 0}$ & 5.29 & -- & - & - \\
$\mathrm{C}_{140}$ & 6.00 & 3.04 & 3.70 & 1.67 \\
$\mathrm{C}_{14: 1}$ & 3.16 & -- & -- & - \\
$\mathrm{C}_{16: 0}$ & 10.77 & 14.79 & 9.95 & 45.26 \\
$\mathrm{C}_{16: 1}$ & 5.24 & 2.87 & 6.94 & 2.78 \\
$\mathrm{C}_{171}$ & 3.13 & -- & -- & -- \\
$\mathrm{C}_{17: 2}$ & 1.76 & -- & - & - \\
$\mathrm{C}_{18: 0}$ & 7.73 & -- & 1.98 & 12.27 \\
$\mathrm{C}_{18: 1}$ & 11.54 & 6.35 & 4.76 & 6.21 \\
$\mathrm{C}_{18: 2}$ & 9.30 & 5.77 & 4.29 & 9.79 \\
$\mathrm{C}_{18: 3}$ & 5.00 & 4.71 & 3.44 & -- \\
$\mathrm{C}_{20: 0}$ & 6.14 & -- & 13.40 & -- \\
$\mathrm{C}_{20: 1}$ & -- & 31.25 & 2.76 & 5.86 \\
$\mathrm{C}_{20: 3}$ & 7.38 & -- & -- & -- \\
$\mathrm{C}_{20: 4}$ & -- & 10.62 & 17.00 & 7.46 \\
$\mathrm{C}_{20: 5}$ & -- & 20.60 & 15.99 & 2.77 \\
$\mathrm{C}_{22: 0}$ & 11.36 & -- & -- & -- \\
\hline
\end{tabular}

$0.20 \%$ on wet weight basis. Glycolipids (MGDG, DGDG and SQDG) were $1.38 \%$ and $1.96 \%$ of dry sample-1 and sample-2, respectively. On the other hand, in the samples digested with abalone enzyme, glycolipids were $2.45 \%$ and $2.75 \%$ of dry sample-1 and sample- 2 , respectively. The lipid extraction assisted with herbivorous digestive enzymes is an effective method for obtaining whole complex lipids. MGDG, DGDG and SQDG were nearly $15 \%$, $15 \%$ and $68 \%$, respectively in complex lipid in both samples (Fig. 1). SQDG typically constitutes about 5\% among the total acyl lipids in higher plant leaves. In certain algae, SQDG is a major lipid component and levels of up to $29 \%$ of total lipids have been reported (Padley et al., 1994).

Fatty acid compositions of simple lipids, MGDG, DGDG and SQDG of $S$. horneri are shown in Table 2. Saturated fatty acids 16:0 and 22:0 and monounsaturated fatty acid 18:1 were the major fatty acids for simple lipids. The findings agree with that of Cohen et al. (1989) who found

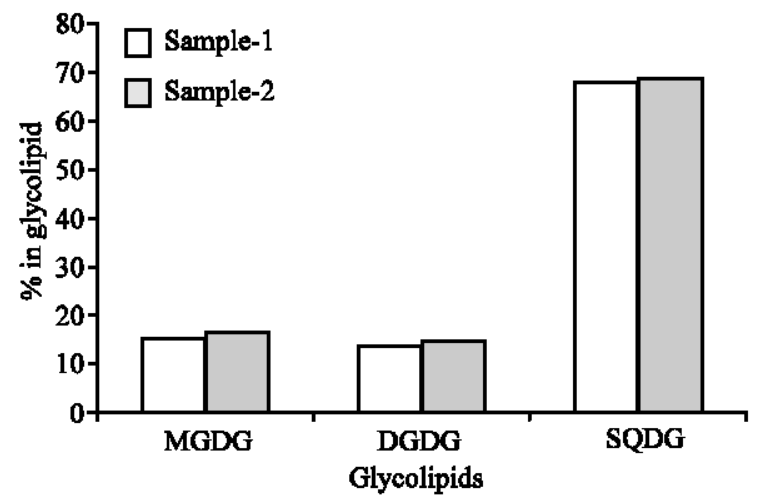

Fig. 1: Percentage of MGDG, DGDG and SQDG in glycolipids of $S$. horneri

nearly similar results for the red algas Prophyridium cruentum except 20:5. The major fatty acids of MGDG were 16:0, 18:1, 20:1, 20:4 and 20:5 in S. horneri. The findings coincide with that of Arao and Yamada (1989) who found nearly similar results for S. ringgoldianum. On the other hand, Murakami et al. (2003) found 18:0, 18:1 and $18: 3$ as the major fatty acids in MGDG of a green vegetable, spinach (Spinacia oleracea L.). The major fatty acids of DGDG were 16:0, 20:0, 20:4 and 20:5 for $S$. horneri. The results were also similar to Arao and Yamada (1989) except 18:3. On the contrary, Murakami et al. (2003) reported that 16:0 was the major fatty acid in DGDG of spinach Spinacia oleracea. The major fatty acids of SQDG were 16:0, 18:0, 18:1, 18:2 and 20:4. Similarly, the results agree with the findings of Cohen et al. (1989). But Murakami et al. (2003) reported that 16:0 and 18:3 were the major fatty acids in SQDG of spinach Spinacia oleracea. From the results, algae are good sources for the glycolipids containing highly unsaturated fatty acids, compared to terrestrial plants. It may be concluded that $S$. horneri is a potential source of valuable glycolipids. Further experimentation should be conducted with the samples of all seasons through a year for getting biochemical variation in a year.

\section{Acknowledgments}

This work was partially supported by the grant of 2001 , Academic Frontier Promotion Project, Hokkaido Asai Gakuen University. The authors also wish to acknowledge the contribution of Chisato Sekikawa and Seigo Ono in offering the valuable suggestion during the course of this work.

\section{References}

Arao, T. and M. Yamada, 1989. Positional distribution of fatty acids in galactolipids of algae. Phytochemistry, 28: 805-810. 
Becker, E.W., 1994. Microalgae: biotechnology and microbiology. In Baddiley J., N.H. Carey, I.J. Higgins and W.G. Potter (Eds.). Cambridge studies in biotechnology, vol. 10. Cambridge University Press, Cambridge.

Bligh, E.G. and W.J. Dyer, 1959. A rapid method of total lipid extraction and purification. Can. J. Biochem. Physiol., 37: 911-917.

Borowitzka, M.A., 1988. Fat, oils and hydrocarbons. In Borowitzka, L.J. (Eds.). Microalgae biotechnology. Cambridge University Press, Cambridge pp: 257-287.

Callegari, J.P., 1989. Feu vert pour les microalgues. Biotutur., 76: 25-40.

Caughey, G.E., E. Mantzioris, R.A. Gibson, L.G. Cleland and M.J. James, 1996. The effect of human tumor necrosis factor and interleukin 1 production of diets enriched in n-3 fatty acids from vegetable oil or fish oil. Am. J. Clin. Nutr., 63:116-122.

Cohen, Z., A. Vonshak and A. Richmond, 1988. Effects of environmental conditions of fatty acid composition of red algae Porphyridium cruentum: correlation to growth rate. J. Phycol., 24: 328-332.

Henrikson, R., 1989. New medical research with Spirulina. In Ronose Enterprises, Inc. (Ed.) Earth Food Spirulina. Laguna Beach California, pp: 61-73.

Murakami, C., T. Kumagai, T. Hada, U. Kanekazu, S. Nakazawa, S. Kamisuki, N. Maeda, X. Xu, H. Yoshida, F. Sugawara, K. Sakaguchi and Y. Mizushina, 2003. Effects of glycolipids from spinach on mammalian DNA polymerases. Bioche. Pharma., 65: 259-267.
Nizamuddin, M., 1962. Classification and distribution of the Fucales. Bot. Mar., 4:191-203.

Padley, F.B., F.D. Gunstone and J.L. Harwood. 1994. Occurrence and characteristics of oils and fats. In the lipid handbook. Gunstone, F.D., J.L. Harwood and F.B. Padley. (Eds.) Chapman and Hall, Cambridge, England, pp: 47-223.

Richmond, A., 1990. Large scale microalgal culture and applications. In Round, M. and S. Chapman. (Eds.) Progress in phycological research, Vol. 7. Biopress Ltd., pp: 269-330.

Ricketts, T.R., 1966. On the chemical composition of some unicellular algae. Phytochem., 5: 67-76.

Rodriguez, H. and M.G. Guerrero, 1992. Products and uses of cyanobacteria (blue-green algae). In Villa, T.G. and J. Abalde. (Eds.) Profiles on biotechnology. Universidad de Santiago de Compostela, Santiago, Chile, pp: 247-260.

Tokida, J. and T. Masaki, 1959. Fac. Fish., Hokkaido University, 10: 173-195.

Vagas, M.A., H. Rodriguez, J. Moreno, H. Olivares, A Del Campo, J. Rivas and M.G. Guerrero, 1988. Biochemical composition and fatty acid content of filamentous $\mathrm{N}_{2}$ fixing cyanobacteria. J. Phycol., 34: 812-817. 